\title{
Association between nutrients and metabolic syndrome in middle-aged Korean women
}

\author{
Sul Lee' \\ https://orcid.org/0000-0002-9107-4296 \\ Hyun Joo Lee ${ }^{1}$ \\ https://orcid.org/0000-0002-1223-4387 \\ Seung Chul Kim \\ https://orcid.org/0000-0002-8174-9931 \\ Jong Kil Joo ${ }^{1}$ \\ https://orcid.org/0000-0002-6338-1512
}

${ }^{1}$ Department of Obstetrics and Gynecology, Pusan National University School of Medicine, Pusan National University Hospital Medical Research Institute, Busan, Korea

\begin{abstract}
Objectives: The aim of this study was to evaluate the association between nutritional intake and metabolic syndrome in otherwise healthy middle-aged Korean women. Subjects and methods: Retrospectively, medical records were reviewed for nutritional intake of 2,182 Korean women who had undergone routine medical check-ups from 2010 to 2016 at Pusan National University Hospital. The patients who met diagnostic criteria for metabolic syndrome based on NCEP-ATPIII were included, and each of the patients was assessed through self-report questionnaires and individual interview with a health care provider. The recommended dietary allowance (RDA) for women in Republic of Korea was based on 2015 criteria discussed in Dietary Reference Intake for Koreans, organized by the Ministry of Health andWelfare. Results: Through univariate analysis, daily calorie, protein, fat, and carbohydrate consumption were significantly higher and exceeded RDA in the patients with metabolic syndrome; other than major nutrients, iron, vitamin B2, and niacin were also consumed in excess of the RDA in these patients. Multivariate analysis showed that carbohydrate consumption, along with protein and vitamin B2, were significantly higher in the patients with metabolic syndrome. Conclusion: In middle-aged Korean women, high consumption of carbohydrates, along with protein and vitamin B2, was found to have a statistically significant association with the presence of metabolic syndrome. Arch Endocrinol Metab. 2020;64(3):298-305
\end{abstract}

Keywords

Metabolic syndrome; nutrients; dietary pattern; carbohydrate; protein
Correspondence to:

Jong Kil Joo

Pusan National University Hospital,

Department of Obstetrics and

Gynecology

49241, Seo-Gu, Gudeck-ro179

Busan, Korea

jongkilj@hanmail.net

Received on Dec/12/2019

Accepted on Apr/1/2020

DOI: 10.20945/2359-3997000000252

\section{INTRODUCTION}

$\mathrm{M}$ etabolic syndrome (MetS), one of the largestgrowing health concerns worldwide, is a cluster of diseases based on physiological consequences of insulin resistance including obesity, hypertension, diabetes mellitus, and dyslipidemia (1). As a degenerative disorder that worsens with age, its close relation to cardiovascular risks along with increased morbidity and mortality is widely known, and patients require education and lifelong management (2).

One of the major issues in public education for MetS patients is diet; dietary patterns and nutrients intake likely determine the development and/or progress of the disease, even seemingly accelerating its prevalence (2-6). However, it is not clear exactly which nutrients affect MetS. Several nutritional factors have been reported to be associated with MetS, but the results are not consistent $(5,7,8)$.
For such reasons, numerous national, comprehensive studies on dietary patterns and nutrients in MetS patients are now being conducted worldwide; in the United States and Canada, comparative studies on dietary patterns and nutrients intake of general population and patients with MetS have found parallel associations between higher intake of saturated fatty acids - saturated foods and soft drinks, for examples - and higher risk for MetS $(9,10)$. Similarly, research in East Asian countries including China and Japan has shown that a high-protein/cholesterol diet is associated with higher prevalence of MetS; researchers have emphasized the importance of developing nutritional intervention for not only management but also preventive purposes (11-13).

In South Korea, the prevalence of MetS is increasing, as it is in other Asian countries. From 1998 to 2012 , the prevalence rose from $24.9 \%$ to $37 \%$ 
$(3,14)$. Over the past several decades, eating habits in Korea have become westernized (high intakes of beef, sugar, and fat) and can be easily ingested through a variety of automated processes. In this process, a meat diet preference became more favored than vegetarian diets, and carbohydrate consumption increased (15).

Therefore, in this study, we attempted to determine how individuals with metabolic syndrome take nutrients and how it differs from how individuals without metabolic syndrome do so.

\section{SUBJECTS AND METHODS}

\section{Study cohort and design}

This was a retrospective study of 2,182 women who underwent health screening examinations at the Pusan National University Hospital Health Promotion Center in South Korea between 2010 and 2016. This period, about 4,000 female patients visited the Health Promotion Center of Pusan National University Hospital, of which 2,200 middle-aged women (aged 30-74) were selected. When they first visited, we offered a self-administered questionnaire including each participant's demographics, lifestyle, medical history, and diet. All the participants agreed with their informed consent that their medical records would be used in this study. After completing the questionnaire, the nutritionist checked again through individual interviews, so few surveys were missing, and missing FFQs were excluded from the data. Therefore, a total of 2,182 people were selected, except for 18 surveys of some inaccurate FFQs. We divided them into patients with and without MetS: 1,805 women without MetS and 377 women with MetS. This study was approved by the Institutional Review Board (IRB) of Pusan National University Hospital (H-1906-023-080).

\section{Definition of metabolic syndrome}

We used the National Cholesterol Education Program's Adult Treatment Panel III report to define MetS (16); women needed to meet at least three of the following five criteria; (1) abdominal circumference over $80 \mathrm{~cm}$ (for Asian women), (2) TG level over $150 \mathrm{mg} / \mathrm{dL}$, (3) HDL-C less than $50 \mathrm{mg} / \mathrm{dL}$, (4) FBG over 110 $\mathrm{mg} / \mathrm{dL}$ or DM, and (5) blood pressure over 130/85 or hypertension medication (17).

\section{Nutrition Intake survey}

We conducted the nutrition survey through direct interviews with patients who visited the Pusan National University Hospital Health Promotion Center. The questionnaire items were prepared based on the revised edition of Health Promotion of Koreans in 2004. We calculated the nutrition data for each food using a semiquantitative food frequency survey.

The FFQ we used was based on Korean National Health and Nutrition Survey form. This FFQ is a format commonly used in other nutrient articles (18). It consists of 32 questions and results were expressed as a sum of weekly food consumption based on 1 serving size. 32 questions were composed of grains, meat and fishes, vegetables, fats, milk products, fruits, sugars, and others. Grains include bread, sponge cake, cake, crackers, biscuits, cooked rice, noodle, rice, potato, etc. Meat and fishes include beef, pork, chicken, low fat fishes, squid, shrimp, crab, shellfish, oyster, anchovy, dried white bait, eggs, medium fat fishes, tofu, black bean, hams, high fat fishes, rib, sausage, eel. Vegetables include green-yellow, white, young radish, radish leaves, kimchi, diced radish kimchi, seaweeds. Fats include nuts, plant oils, mayonnaise, butter, creams, bacon. Milk products include milk, yoghurt, ice cream. Fruits include fresh fruit, fresh juice. Others include sugars (sugar/syrup/sweetened drink/candy/chocolate) and others (fast-foods, instant noodle, Korean stews, coffee/tea). The daily recommended dietary allowances of Koreans were based on 2015 criteria for Dietary Reference Intake for Koreans (2015 KDRIs) organized by the Ministry of Health and Welfare. We divided each nutrient into the actual daily intake and the percentage of actual intake compared with daily recommended nutrients intake (RNI) in percentage.

Also, nutrients analysis used at Pusan National University Hospital software is a program developed by itself, but this program is based on CAN-pro 3.0 made by the Korean Nutrition Society. This program is widely used in Korea $(19,20)$.

\section{Statistical analysis}

In this study, we used SAS 9.3 for statistical analysis, the independent $t$ test or Wilcoxon rank-sum test for continuous variables and the chi-square test for categorical variables. To calculate the area under the receiver operating characteristic curve, we used a logistic regression model. We considered two-sided values of $\mathrm{P}<0.05$ statistically significant. 


\section{RESULTS}

\section{Demographics and characteristics}

Characteristics of the patients both with and without MetS are shown in Table 1. We found statistically significant differences in most parameters but not the following: smoking, total bilirubin, direct bilirubin, albumin, creatinine, kcal, protein $(\mathrm{g})$, calcium $(\mathrm{mg})$, calcium (percent), vitamin A (Retinol Equivalent, RE), vitamin A (percent), vitamin B2 $(\mathrm{mg})$, vitamin $\mathrm{C}(\mathrm{mg})$, vitamin $\mathrm{C}$ (percent). With the physical measurements, all parameters were higher in patients with MetS. The syndrome was more commonly observed in menopausal women as well as in women with diabetes mellitus, high blood pressure, and dyslipidemia.

Table 1. Demography and characteristics

\begin{tabular}{|c|c|c|c|c|}
\hline Variables & $\begin{array}{c}\text { Total } \\
(n=2,182)\end{array}$ & $\begin{array}{l}\text { Without MetS } \\
(n=1,805)\end{array}$ & $\begin{array}{l}\text { With MetS } \\
(n=377)\end{array}$ & ${ }^{\star} p$ \\
\hline \multicolumn{5}{|l|}{ Clinical characteristics } \\
\hline Age $(y r)^{*}$ & $53.09(10.00)$ & $51.68(9.69)$ & $59.86(8.62)$ & $<.0001$ \\
\hline Body weight $(\mathrm{kg})^{\star}$ & $56.77(7.89)$ & $55.6(7.01)$ & $62.38(9.33)$ & $<.0001$ \\
\hline Percent body fat (\%) & $29.20[26.00,32.30]$ & $28.40[25.30,31.30]$ & $33.10[30.90,35.50]$ & $<.0001$ \\
\hline $\mathrm{WC}(\mathrm{cm})^{*}$ & $78.76(8.46)$ & $77.07(7.49)$ & $86.88(8.13)$ & $<.0001$ \\
\hline $\mathrm{BMI}\left(\mathrm{kg} / \mathrm{m}^{2}\right)^{*}$ & $22.64(3.03)$ & $22.07(2.58)$ & $25.36(3.54)$ & $<.0001$ \\
\hline Height $(\mathrm{cm})^{\star}$ & $158.40(5.26)$ & $158.72(5.10)$ & $156.86(5.74)$ & $<.0001$ \\
\hline Body muscle $(\mathrm{kg})^{*}$ & $36.73(3.51)$ & $36.50(3.27)$ & $37.83(4.34)$ & $<.0001$ \\
\hline Skeletal muscle $(\mathrm{kg})^{\star}$ & $18.52(3.81)$ & $18.25(3.69)$ & $19.80(4.10)$ & $<.0001$ \\
\hline Menopause (\%) & & & & $<.0001$ \\
\hline Pre-menopause & $818(37.49)$ & 762 (42.22) & $56(14.85)$ & \\
\hline Post-menopause & $1364(62.51)$ & $1043(57.78)$ & $321(85.15)$ & \\
\hline Hypertension (\%) & & & & $<.0001$ \\
\hline without hypertension & 1803 (82.63) & 1635 (90.58) & $168(44.56)$ & \\
\hline with hypertension & $379(17.37)$ & $170(9.42)$ & $209(55.44)$ & \\
\hline DM (\%) & & & & $<.0001$ \\
\hline without DM & 2092 (95.88) & 1781 (98.67) & $311(82.49)$ & \\
\hline with DM & $90(4.12)$ & $24(1.33)$ & $66(17.51)$ & \\
\hline Hyperlipidemia (\%) & & & & $<.0001$ \\
\hline Without Hyperlipidemia & $1841(84.37)$ & 1617 (89.58) & $224(59.42)$ & \\
\hline With Hyperlipidemia & 341 (15.63) & $188(10.42)$ & $153(40.58)$ & \\
\hline Smoking (\%) & & & & 0.300 \\
\hline Non-smoking & $2072(94.96)$ & $1710(94.74)$ & 362 (96.02) & \\
\hline Smoking & $110(5.04)$ & $95(5.26)$ & $15.00(3.98)$ & \\
\hline Group (\%) & & & & $<.0001$ \\
\hline Premenopause, no MetS & 762 (34.92) & 762 (42.22) & $0(0.00)$ & \\
\hline Premenopause, MetS & $56(2.57)$ & $0(0.00)$ & $56(14.85)$ & \\
\hline Postmenopause, no MetS & $1043(47.80)$ & $1043(57.78)$ & $0(0.00)$ & \\
\hline Postmenopause, MetS & $321(14.71)$ & $0(0.00)$ & $321(85.15)$ & \\
\hline \multicolumn{5}{|l|}{ Laboratory parameters } \\
\hline $\mathrm{LDH}(\mathrm{IU} / \mathrm{L})^{*}$ & $270.12(95.77)$ & $265.91(94.03)$ & $290.29(101.45)$ & $<.0001$ \\
\hline Total_Bilirubin (mg/dL)* & $0.87(0.37)$ & $0.87(0.37)$ & $0.85(0.36)$ & 0.239 \\
\hline Direct_Bilirubin (mg/dL)* & $0.22(0.09)$ & $0.22(0.09)$ & $0.21(0.08)$ & 0.051 \\
\hline Total_Protein $(\mathrm{g} / \mathrm{dL})^{\star}$ & $7.16(0.41)$ & $7.15(0.41)$ & $7.23(0.40)$ & $<.0001$ \\
\hline Albumin $(\mathrm{g} / \mathrm{dL})^{*}$ & $4.41(0.26)$ & $4.41(0.26)$ & $4.42(0.26)$ & 0.608 \\
\hline BUN $(\mathrm{mg} / \mathrm{dL})^{\star *}$ & $13.50[11.20,16.00]$ & $13.40[11.20,15.90]$ & $14.10[11.30,16.70]$ & 0.008 \\
\hline
\end{tabular}




\begin{tabular}{|c|c|c|c|c|}
\hline Variables & $\begin{array}{c}\text { Total } \\
(\mathrm{n}=\mathbf{2 , 1 8 2})\end{array}$ & $\begin{array}{l}\text { Without MetS } \\
(n=1,805)\end{array}$ & $\begin{array}{c}\text { With MetS } \\
(n=377)\end{array}$ & ${ }^{*} p$ \\
\hline Creatinine $(\mathrm{mg} / \mathrm{dL})^{\star *}$ & $0.69[0.63,0.77]$ & $0.69[0.63,0.77]$ & $0.70[0.62,0.79]$ & 0.590 \\
\hline Calculated GFR (mL/min)* & $90.21(17.84)$ & $90.85(17.25)$ & $87.16(20.16)$ & 0.001 \\
\hline r_GTP $(I U / L)^{\star *}$ & $16.00[12.00,23.00]$ & $15.00[12.00,21.00]$ & $22.00[16.00,32.00]$ & $<.0001$ \\
\hline Calcium (mg/dL)* & $9.41(0.38)$ & $9.39(0.38)$ & $9.48(0.38)$ & $<.0001$ \\
\hline$A L P(I U / L)^{\star \star}$ & $66.00[52.00,91.00]$ & $63.00[50.00,87.00]$ & $75.00[60.00,116.00]$ & $<.0001$ \\
\hline Total_Cholesterol (mg/dL)* & $201.00(37.00)$ & 199.37 (34.88) & 208.82 (45.06) & $<.0001$ \\
\hline Triglyceride $(\mathrm{mg} / \mathrm{dL})^{\star \star}$ & $81.00[59.00,113.00]$ & $74.00[56.00,100.00]$ & $129.00[94.00,177.00]$ & $<.0001$ \\
\hline HDL_Cholesterol (mg/dL)* & $62.28(15.45)$ & $64.93(14.76)$ & $49.6(12.01)$ & $<.0001$ \\
\hline LDL_Cholesterol (mg/dL)* & 127.09 (35.28) & $124.55(33.1)$ & 139.26 (42.24) & $<.0001$ \\
\hline Free_Fatty_Acid (uEq/L) $)^{\star \star}$ & $598.00[434.00,803.00]$ & $585.00[425.00,794.00]$ & $651.00[466.00,842.00]$ & 0.001 \\
\hline Glucose $(\mathrm{mg} / \mathrm{dL})^{\star *}$ & $86.00[81.00,93.00]$ & $85.00[80.00,91.00]$ & $97.00[88.00,108.00]$ & $<.0001$ \\
\hline Insulin_RIA (ulU/mL)** & $4.17[3.37,5.18]$ & $4.01[3.29,4.90]$ & $5.13[4.20,7.53]$ & $<.0001$ \\
\hline $\mathrm{CRP}(\mathrm{mg} / \mathrm{dL})^{\star \star}$ & $0.04[0.02,0.09]$ & $0.03[0.02,0.07]$ & $0.08[0.04,0.15]$ & $<.0001$ \\
\hline IDMS_MDRD_ckd (\%) & & & & $<.0001$ \\
\hline Without CKD & 2130 (97.62) & 1780 (98.61) & $350(92.84)$ & \\
\hline With CKD & $52(2.38)$ & 25 (1.39) & $27(7.16)$ & \\
\hline \multicolumn{5}{|c|}{ Nutritional data (derived from the FFQ) } \\
\hline $\mathrm{Kcal}^{*}$ & $1754.13(306.17)$ & $1751.94(297.22)$ & 1764.61 (346.08) & 0.509 \\
\hline Kcal_percent** & $101.76[88.48,118.04]$ & $99.50[87.21,113.98]$ & $115.82[97.54,130.52]$ & $<.0001$ \\
\hline Protein_g* & $68.00(14.81)$ & $67.99(14.49)$ & $68.07(16.26)$ & 0.932 \\
\hline Protein_percent* & $106.80(27.65)$ & 104.44 (26.98) & $118.12(28.05)$ & $<.0001$ \\
\hline Fat_g* & $44.86(12.96)$ & $45.28(12.78)$ & 42.89 (13.62) & 0.001 \\
\hline Fat_percent* & $118.53(36.7)$ & $117.21(36.11)$ & $124.87(38.83)$ & $<.0001$ \\
\hline Carbohydrate_g** & $269.50[235.50,302.30]$ & $268.30[235.75,300.30]$ & $274.95[235.30,316.45]$ & 0.007 \\
\hline Carbohydrate_percent** & $95.42[81.58,113.26]$ & $93.16[80.42,108.22]$ & $112.05[91.13,128.70]$ & $<.0001$ \\
\hline Calcium_mg* & 898.08 (243.61) & $893.78(243.40)$ & $918.68(243.86)$ & 0.071 \\
\hline Calcium_percent* & $128.30(34.80)$ & $127.68(34.77)$ & $131.24(34.84)$ & 0.071 \\
\hline Iron_mg* & $19.32(4.61)$ & $19.23(4.55)$ & $19.75(4.84)$ & 0.048 \\
\hline Iron_percent* & $146.58(41.90)$ & $143.96(41.50)$ & $159.13(41.59)$ & $<.0001$ \\
\hline VitA_RE ${ }^{*}$ & $1091.58(323.16)$ & 1086.81 (322.73) & 1114.39 (324.66) & 0.132 \\
\hline VitA_percent* & $155.75(46.21)$ & $155.03(46.15)$ & 159.20 (46.38) & 0.112 \\
\hline VitB1_mg* & $1.14(0.23)$ & $1.14(0.23)$ & $1.19(0.25)$ & $<.0001$ \\
\hline Vit B1_percent** & $86.15[75.38,98.46]$ & 85.50 [74.62, 96.92] & $90.77[76.92,103.08]$ & $<.0001$ \\
\hline VitB2_mg* & $1.49(0.40)$ & $1.49(0.40)$ & $1.52(0.40)$ & 0.148 \\
\hline Vit B2_percent* & 98.48 (26.71) & $97.90(26.63)$ & 101.27 (26.94) & 0.026 \\
\hline Niacin_mg* & $17.44(3.42)$ & $17.32(3.33)$ & $17.99(3.77)$ & 0.002 \\
\hline Niacin_percent* & 122.52 (24.55) & 121.34 (23.93) & 128.15 (26.66) & $<.0001$ \\
\hline VitC_mg* & 79.49 (24.79) & $79.12(24.66)$ & $81.27(25.38)$ & 0.126 \\
\hline vitC_percent* & $113.2(35.87)$ & 112.65 (35.69) & 115.85 (36.66) & 0.115 \\
\hline Alcohol_kcal** & $0.00[0.00,14.29]$ & $0.00[0.00,14.29]$ & $0.00[0.00,0.00]$ & 0.003 \\
\hline
\end{tabular}

Data are presented as means. ${ }^{*}$, mean(SD); ${ }^{* *}$, mean[IQR]; percent, daily intake/daily recommendation intake quantity $\times 100$. $p$ is by independent $t$ test.

MetS: metabolic syndrome; WC: waist circumference; BMl: body mass index; DM: diabetes mellitus; LDH: lactate dehydrogenase; BUN: blood urea nitrogen; MDRD: modification of diet in renal disease; IDMS: isotope dilution mass spectrometry; $\gamma$-GTP: gamma-glutamyltransferase; ALP: alkaline phosphatase; HDL: high density lipoprotein; LDL: Iow density lipoprotein; RIA: radioimmunoassay; CRP: C-reactive protein; Kcal, kilocalories; Vit: Vitamin. 


\section{Relationship MetS and nutrition}

In terms of nutrients intake, the percentage of total calories in the women with metabolic syndrome was higher and the intake of fat, protein, carbohydrate, iron, vitamin $\mathrm{Bl}$ and niacin was also higher. In univariate analysis, the intake of energy-related factors such as caloric intake, protein, fat and sugar was statistically significantly higher than the recommended daily allowance (RDA) in MetS patients. Iron (mg) and vitamin B2 (mg) in daily total intake quantity and niacin (mg and percent) in both daily total intake quantity and percentage of the total daily intake compared with the RDA also showed statistically significant results. However, calcium(mg and percent), vitamin A (mg and percent), and vitamin $\mathrm{C}$ ( $\mathrm{mg}$ and percent) in both daily total intake quantity and percentage of the total daily intake compared with the RDA and alcohol intake (kcal) in daily total intake, vitamin Bl (percent) in daily recommended did not produce statistically significant results (Table 2). By multivariate analysis, only protein(percent), carbohydrate (percent), and vitamin B2 (percent) in percentage of the total daily intake compared with the RDA were statistically significantly higher in patients with MetS (Table 3).

\section{DISCUSSION}

Because MetS is a degenerative disease, women with MetS are older, as shown in Table 1. Likewise, factors that reflect lifestyle or diet habits such as BMI, WC, and body weight were also higher in women with MetS. In univariate analysis, carbohydrate, protein, fat, iron, vitamin $\mathrm{A}$, vitamin $\mathrm{B} 2$, and niacin were more positively correlated with MetS. However, on multivariate analysis, only protein and carbohydrate were associated with MetS in percentage of the total daily intake compared with the RDA.

Table 2. Logistic regression (univariate) analysis of nutrition and metabolic syndrome

\begin{tabular}{|c|c|c|c|c|c|}
\hline \multirow{2}{*}{ Response } & \multirow{2}{*}{ Predictors } & \multirow{2}{*}{ OR } & \multicolumn{2}{|c|}{$95 \%$ Cl } & \multirow{2}{*}{ p-value } \\
\hline & & & Lower & Upper & \\
\hline \multirow[t]{23}{*}{ Mets } & Kcal_kcal & 1.000 & 1.000 & 1.000 & 0.465 \\
\hline & Kcal_percent & 1.021 & 1.016 & 1.026 & $<.0001$ \\
\hline & Protein_g & 1.000 & 0.993 & 1.008 & 0.926 \\
\hline & Protein_percent & 1.018 & 1.014 & 1.022 & $<.0001$ \\
\hline & Fat_g & 0.986 & 0.977 & 0.994 & 0.001 \\
\hline & Fat_percent & 1.006 & 1.003 & 1.009 & $<.0001$ \\
\hline & Carbohydrate_g & 1.003 & 1.001 & 1.005 & 0.003 \\
\hline & Carbohydrate_percent & 1.014 & 1.010 & 1.019 & $<.0001$ \\
\hline & Calcium_mg & 1.000 & 1.000 & 1.001 & 0.071 \\
\hline & Calcium_percent & 1.003 & 1.000 & 1.006 & 0.071 \\
\hline & Iron_mg & 1.024 & 1.000 & 1.049 & 0.048 \\
\hline & Iron_percent & 1.008 & 1.006 & 1.011 & $<.0001$ \\
\hline & VitA_RE & 1.000 & 1.000 & 1.001 & 0.132 \\
\hline & vitA_percent & 1.002 & 1.000 & 1.004 & 0.112 \\
\hline & VitB1_mg & 2.497 & 1.547 & 4.031 & $<.0001$ \\
\hline & Vit B1_percent & 1.002 & 0.999 & 1.004 & 0.165 \\
\hline & VitB2_mg & 1.223 & 0.931 & 1.607 & 0.148 \\
\hline & Vit B2_percent & 1.005 & 1.001 & 1.009 & 0.026 \\
\hline & Niacin_mg & 1.057 & 1.024 & 1.092 & 0.001 \\
\hline & Niacin_percent & 1.011 & 1.007 & 1.016 & $<.0001$ \\
\hline & VitC_mg & 1.003 & 0.999 & 1.008 & 0.126 \\
\hline & vitC_percent & 1.002 & 0.999 & 1.006 & 0.115 \\
\hline & Alcohol_kcal & 1.000 & 0.999 & 1.001 & 0.773 \\
\hline
\end{tabular}

MetS: metabolic syndrome; Kcal: kilocalories; Vit: vitamin; OR: odds ratio, percent, daily intake/daily recommendation intake quantity $\times 100$. 
Table 3. Logistic regression(multivariate) analysis of nutrition and metabolic syndrome

\begin{tabular}{|c|c|c|c|c|c|}
\hline \multirow{2}{*}{ Response } & \multirow{2}{*}{ Predictors } & \multirow{2}{*}{ OR } & \multicolumn{2}{|c|}{$95 \% \mathrm{Cl}$} & \multirow{2}{*}{ p-value } \\
\hline & & & Lower & Upper & \\
\hline \multirow[t]{7}{*}{ Mets } & Age & 1.095 & 1.078 & 1.112 & $<.0001$ \\
\hline & Kcal_percent & 1.005 & 1.000 & 1.010 & 0.065 \\
\hline & Protein_percent & 1.011 & 1.004 & 1.017 & 0.001 \\
\hline & Carbohydrate_percent & 1.003 & 1.000 & 1.006 & 0.026 \\
\hline & Iron_percent & 0.998 & 0.991 & 1.005 & 0.586 \\
\hline & VitB2_percent & 0.996 & 0.987 & 1.005 & 0.391 \\
\hline & Niacin_percent & 1.000 & 0.992 & 1.007 & 0.957 \\
\hline
\end{tabular}

MetS: metabolic syndrome; Kcal: kilocalories; Vit: vitamin; OR: odds ratio; percent, daily intake/daily recommendation intake quantity $\times 100$.

Authors of several studies have reported the association between protein intake and incidence of MetS. In a study on Koreans, being male had a positive correlation with MetS when the diet was high in meat (multivariate-adjusted PR of the highest group compared with the lowest group: $2.15,95 \% \mathrm{CI}: 1.10-4.21$, $\mathrm{p}$ for trend $=0.005)$. However, women's dietary patterns were not related to MetS (3). In Chinese adults, higher scores for the high-protein/cholesterol pattern were associated with higher prevalence of MetS (OR for the extreme quartile: $1.36,95 \% \mathrm{CI}, 1.10-1.68, \mathrm{p}$ for trend $<0.01)$. High-protein/cholesterol pattern includes high intakes of animal offal, animal blood, and sausage (11). Most of the researchers who analyzed the dietary patterns of people with MetS found an association with high protein intake. In this study, however, we found that women with MetS took in more protein than the recommended daily protein intake but no connection with total amount of protein intake.

In $2015 \mathrm{KDRI}$, the appropriate energy ratio is 55\%$65 \%$ for carbohydrates. In our data, total/without MetS/with MetS was 61.45\%/61.25\%/62.32\% for carbohydrates, respectively. Our data did not exceed AMDR in all groups, but it is higher intake of carbohydrate in women with MetS compared to other groups. Korean foods have a higher proportion of carbohydrates than Western foods, and in Korea, the proportions of energy from carbohydrates, $26.0 \%$ for men and $25.2 \%$ for women, were in the recommended range, whereas $58.0 \%$ of men and $60.0 \%$ of women exceeded AMDR from carbohydrates (65\%) (21). Higher carbohydrate intake (> $80 \%$ of energy from total intake quantity) is associated with MetS in men, but the relationship is not statistically significant in women (21). According to a paper based on the 2005 Korean National Health and Nutrition Examination
Survey, the traditional Korean diet (high carbohydrate and low animal fat with ample plant foods) may affect the incidence of MetS (22).

High carbohydrate consumption may be related with insulin resistance; people with pathological insulin resistance have a higher risk of developing MetS and are more likely to progress to DM (23). Women with insulin resistance had significantly higher total carbohydrate intake and energy from carbohydrates than did women who did not have insulin resistance (24). Other studies have shown that excessive carbohydrate intake can comprise a relatively low-fat diet, which in turn can reduce high-density lipoprotein cholesterol (25). Also, consumption of refined carbohydrates, such as white rice, can cause increased abdominal circumference (26). All these results suggest high carbohydrate consumption as a risk factor for development of MetS. Our study also showed that increased carbohydrate intake in women was associated with increased prevalence of MetS.

Metabolic syndrome is also associated with energyrelated nutrients such as proteins and carbohydrates, as well as co-factors that affect metabolism such as vitamins and minerals. Vitamin B2 (riboflavin) is known to be essential for coenzyme synthesis for glucose, fatty acids, glycerol, and amino acid for energy (27). In a mouse experiment, riboflavin deficiency causes adipocyte lipolysis and apoptosis, leading consequently to the severe chronic inflammation that accompanies obesity (28). Research on humans has not yet produced results. In our study, univariate analysis showed that overintake of vitamin B2 was positively related to MetS, but the relationship was not statistically significant in multivariate analysis.

Vitamin B3 (niacin) is known to increase the levels of HDL cholesterol and reduce triglyceride and LDL cholesterol levels. However, it is reported that diabetic 
patients may exacerbate their blood glucose control status (29). Niacin, also known as methyl-consumer, is toxic through various mechanisms including glucose intolerance, insulin resistance, elevated liver enzymes, fatty liver, and steatosis (30). In 2010, Li and cols. reported a strong lag-correlation between obesity, diabetes prevalence, and capita consumption of niacin in the United States (31). In our study, on univariate analysis, vitamin B3 was associated with MetS but not on multivariate analysis.

The limitation of our study is that the target sample was relatively small and was based on data from the limited areas of Busan and Gyeongnam of South Korea. We believed that there would be differences in survey methods based on questionnaire preparation because the absolute amount of actual nutrient intake may vary. However, this was a relatively uniform sample because the women we studied likely used similar ingredients and relatively similar recipes in a limited area. Second, there was no analysis of several factors that induce MetS: fat composition, physical activity, and food quality. Third, the relationship between MetS and Menopause was also investigated in Korean middle-aged women, but no analysis was conducted between the two. Next time, this will be followed by a new study analyzing nutrients, MetS and menopause. Fourth, because our data are based only on RNI for each nutrient, there is a lack of adequate assessment for groups above or below RNI in all groups.

In conclusion, MetS is a disease that presents as various diagnoses, and it is probably right to aim at correcting living and dietary habits that lead to MetS rather than for therapeutic purposes themselves. Koreans consume the most carbohydrates in Asian countries, where rice is the staple food. In addition, these carbohydrates mostly are included foods with high glycemic index, such as refined rice, bread, ramen, and noodles. As animal proteins such as pork, chicken, and beef are readily available, protein intake from Koreans also exceeds the recommended amount for most age groups. In Koreans, excessive intake of carbohydrates and proteins is also a problem, but high intake of purified carbohydrates and animal proteins can be more problematic. In our study, the dietary habits of high carbohydrate and high protein were related to MetS, therefore, it will be necessary to convert the intake of carbohydrates and proteins to an appropriate amount of energy and convert to less purified carbohydrates and protein such as soy and fish.
Disclosure: no potential conflict of interest relevant to this article was reported.

\section{REFERENCES}

1. National Cholesterol Education Program (NCEP) Expert Panel on Detection, Evaluation, and Treatment of High Blood Cholesterol in Adults (Adult Treatment Panel III). Third Report of the National Cholesterol Education Program (NCEP) Expert Panel on Detection, Evaluation, and Treatment of High Blood Cholesterol in Adults (Adult Treatment Panel III) final report. Circulation. 2002;106(25):3143-421.

2. Choi JH, Woo HD, Lee JH, Kim J. Dietary patterns and risk for metabolic syndrome in Korean women: a cross-sectional study. Medicine (Baltimore). 2015;94(34):e1424.

3. Woo HD, Shin A, Kim J. Dietary patterns of Korean adults and the prevalence of metabolic syndrome: a cross-sectional study. PLoS One. 2014;9(11):e111593.

4. Pimenta AM, Toledo E, Rodriguez-Diez MC, Gea A, Lopez-Iracheta $\mathrm{R}$, Shivappa N, et al. Dietary indexes, food patterns and incidence of metabolic syndrome in a Mediterranean cohort: The SUN project. Clin Nutr. 2015;34(3):508-14.

5. Bian S, Gao Y, Zhang M, Wang X, Liu W, Zhang D, et al. Dietary nutrient intake and metabolic syndrome risk in Chinese adults: a case-control study. Nutr J. 2013;12:106.

6. Muzio F, Mondazzi L, Sommariva D, Branchi A. Long-term effects of low-calorie diet on the metabolic syndrome in obese nondiabetic patients. Diabetes Care. 2005;28(6):1485-6.

7. Jehn M, Clark JM, Guallar E. Serum ferritin and risk of the metabolic syndrome in U.S. adults. Diabetes Care. 2004;27(10):2422-8.

8. Kim MS, Sohn CM. Analysis of Dietary Inflammatory Index of Metabolic Syndrome in Korean: Data from the Health Examinee Cohort (2012-2014). Korean Journal of Human Ecology. 2016;25(6):823.

9. Mazidi M, Pennathur S, Afshinnia F. Link of dietary patterns with metabolic syndrome: analysis of the National Health and Nutrition Examination Survey. Nutr Diabetes. 2017;7(3):e255.

10. Setayeshgar S, Whiting SJ, Vatanparast H. Metabolic syndrome in Canadian adults and adolescents: prevalence and associated dietary intake. ISRN Obes. 2012;2012:816846.

11. Xia Y, Gu Y, Yu F, Zhang Q, Liu L, Meng G, et al. Association between dietary patterns and metabolic syndrome in Chinese adults: a propensity score-matched case-control study. Sci Rep. 2016;6:34748.

12. Li Y, Zhao L, Yu D, Wang Z, Ding G. Metabolic syndrome prevalence and its risk factors among adults in China: $A$ nationally representative cross-sectional study. PLoS One. 2018;13(6):e0199293.

13. Bahari T, Uemura $H$, Katsuura-Kamano $S$, Yamaguchi $M$, Nakamoto M, Miki K, et al. Nutrient-derived dietary patterns and their association with metabolic syndrome in a Japanese population. J Epidemiol. 2018;28(4):194-201.

14. Lim S, Shin H, Song JH, Kwak SH, Kang SM, Won Yoon J, et al. Increasing prevalence of metabolic syndrome in Korea: the Korean National Health and Nutrition Examination Survey for 1998-2007. Diabetes Care. 2011;34(6):1323-8.

15. Lim H, Kim SY, Wang Y, Lee SJ, Oh K, Sohn CY, et al. Preservation of a traditional Korean dietary pattern and emergence of a fruit and dairy dietary pattern among adults in South Korea: secular transitions in dietary patterns of a prospective study from 1998 to 2010. Nutr Res. 2014;34(9):760-70.

16. Grundy SM, Becker D, Clark LT, Cooper RS, Denke MA, Howard WJ, et al. Third Report of the National Cholesterol Education 
Program (NCEP) Expert Panel on Detection, Evaluation, and Treatment of High Blood Cholesterol in Adults (Adult Treatment Panel III) Final Report. Circulation. 2002;106(25):3143-421.

17. Expert Panel on Detection, Evaluation, and Treatment of High Blood Cholesterol in Adults. Executive summary of the third report of the National Cholesterol Education Program (NCEP) expert panel on detection, evaluation, and treatment of high blood cholesterol in adults (Adult Treatment Panel III). JAMA. 2001;285(19):2486-97.

18. An J, Yoon SR, Lee JH, Kim H, Kim OY. Importance of Adherence to Personalized Diet Intervention in Obesity Related Metabolic Improvement in Overweight and Obese Korean Adults. Clin Nutr Res. 2019;8(3):171-83.

19. You CH, Kim BG, Kim YM, Lee SA, Kim RB, Seo JW, et al. Relationship between Dietary Mercury Intake and Blood Mercury Level in Korea. J Korean Med Sci. 2014;29(2):176-82.

20. Shin HY, Kang HT, Lee JW, Lim HJ. The Association between Socioeconomic Status and Adherence to Health Check-up in Korean Adults, Based on the 2010-2012 Korean National Health and Nutrition Examination Survey. Korean J Fam Med. 2018;39(2):114-121.

21. Lee YJ, Song S, Song Y. High-carbohydrate diets and food patterns and their associations with metabolic disease in the Korean population. Yonsei Med J. 2018;59(7):834-42.

22. Song $Y$, Joung $H$. A traditional Korean dietary pattern and metabolic syndrome abnormalities. Nutr Metab Cardiovasc Dis. 2012;22(5):456-62.

23. Defronzo RA, Ferrannini E. Insulin resistance - a multifaceted syndrome responsible for NIDDM, obesity, hypertension, dyslipidemia, and atherosclerotic cardiovascular-disease. Diabetes Care. 1991;14(3):173-94.
24. Song SJ, Paik HY, Song YJ. The relationship between intake of nutrients and food groups and insulin resistance in Korean adults: Using the Fourth Korea National Health and Nutrition Examination Survey (KNHANES IV, 2007-2009). Korean J Nutr. 2013;46(1):61-71.

25. Carnethon MR, Loria CM, Hill JO, Sidney S, Savage PJ, Liu K, et al. Risk factors for the metabolic syndrome: the Coronary Artery Risk Development in Young Adults (CARDIA) study, 1985-2001. Diabetes Care. 2004;27(11):2707-15.

26. Fogelholm M, Anderssen S, Gunnarsdottir I, Lahti-Koski M. Dietary macronutrients and food consumption as determinants of long-term weight change in adult populations: a systematic literature review. Food Nutr Res. 2012;56.

27. Manore MM. Effect of physical activity on thiamine, riboflavin, and vitamin B-6 requirements. Am J Clin Nutr. 2000;72(2):598s-606s.

28. Mazur-Bialy Al, Pochec E. Vitamin B2 deficiency enhances the pro-inflammatory activity of adipocyte, consequences for insulin resistance and metabolic syndrome development. Life Sci. 2017;178:9-16.

29. Elam MB, Hunninghake DB, Davis KB, Garg R, Johnson $C$, Egan $D$, et al. Effect of niacin on lipid and lipoprotein levels and glycemic control in patients with diabetes and peripheral arterial disease - The ADMIT Study: A randomized trial. J Am Med Assoc. 2000;284(10):1263-70.

30. Chang AM, Smith MJ, Galecki AT, Bloem CJ, Halter JB. Impaired beta-cell function in human aging: response to nicotinic acid-induced insulin resistance. J Clin Endocrinol Metab. 2006;91(9):3303-9.

31. Li D, Sun WP, Zhou YM, Liu QG, Zhou SS, Luo N, et al. Chronic niacin overload may be involved in the increased prevalence of obesity in US children. World J Gastroenterol. 2010;16(19):2378-87. 